\title{
Graphene Oxide from Current Perspectives to Future Applications
}

\author{
Sava Daniel ${ }^{1}$, Gudovan Dragos ${ }^{1}$, Gudovan Iulia Alexandra ${ }^{1,2}$, Sonmez Maria ${ }^{3}$, Ficai Anton ${ }^{1}$, Andronescu \\ Ecaterina $^{1}$ \\ ${ }^{1}$ University POLITEHNICA of Bucharest \\ Splaiul Independentei 313, Bucharest, Romania \\ ${ }^{2}$ National Institute of Endocrinology "C.I. Parhon" \\ B-dul Aviatorilor 34-36, Bucharest, Romania \\ ${ }^{3}$ National Research \& Development Institute for Textiles and Leather - Division: Leather and Footwear Research Institute \\ 93 Ion Minulescu St., Bucharest, Romania \\ dragosgudovan@gmail.com; iuliagudovan@gmail.com
}

\begin{abstract}
In this paper, the development of graphene oxide for environmental applications, following the approaches of different research groups were studied. The results were grouped per three main lines, depollution behaviour and characteristics, novel sensors and sensor materials and toxicity associated with the use of those materials. The main results were of the research has been emphasized, and some perspectives were highlighted for the future in the conclusions. Graphene oxide took a huge leap forward, but in order to gain more knowledge, a unified perspective is still required from all research groups, an unified perspective concerning methods for testing and critical parameters which should not be missed in any depollution study. Graphene oxide has the potential to become a highly produced material, due to the many advantages it brings, as long as it does not add its toxicity and as long as the danger it removes is lesser than the danger we face from using it.
\end{abstract}

Keywords: graphene oxide, water depollution, heavy metal ions, retention characteristics

\section{Introduction}

In the last ten years carbon based materials have received careful attention due to the many advantages they poses, although not always easy to synthesize or industrialize, but with great adsorption behaviour, selectivity when needed through proper chemical or physical modification and biocompatibility in the case of drug delivery or medical implants. In the field of environmental depollution, carbon based materials, mainly graphene and graphene oxide materials, followed a few distinct routes of development, which can be categorized as follows: depollution of drinking and industrial water through adsorption [1-30] or photodegradation [31-36], the analysis of toxic substances in aqueous media through use of novel sensor materials [37-39], better methods for sample preparation involving the use of graphene oxide based materials [40-52] and last but not least the assessment of environmental fate and toxicity of these type of materials [53-60].

Each type of environmental application is an important process, without the ability to successfully assess a potential threat it is virtually impossible to overcome it or even try to devise a long term plan to substantially diminish it. New methods for sample preparation are required, as analytical techniques constantly develop, those techniques are in the need of proper selectivity and sometimes targeted recovery of analytic compounds, targeting which can be compound specific [40-42] (a single compound or a few compounds with great toxicity are pursued) or class specific (the application targets a class of compounds, such as pesticides for example) [43-52]. Some analysis requires the development of better sensors, the proper determination of the concentration in situ being of outmost importance. In those cases, a proper selectivity is required in order to monitor and assess raises in concentration which may cause a need for a response, coupled with a short detection response time [37-39]. The depollution of waters using graphene oxide materials can be done using adsorption characteristics, which can be tuned to filter out a single compound selectively $[1,5,9,10,12,13,21,22,24,28,61]$ or a range of compounds $[2-4,6-8,15-18,20,23,25,27,29]$ or photodegradation, in this case the graphenic material acting as a catalyst for the degradation reaction [31-36]. Of course, the fight for environmental depollution cannot be complete and is useless if in the struggle to remove a toxic component from the environment we add another one which has the potential 
to be more toxic that the one we are aiming to remove. In this case, proper studies must be carried out to ensure, or at least assess the potential of new materials to cause an unwanted environmental impact [53-60].

In the present study, we aim to summarise the research made in the past few years (2013-2107) in the field of graphene oxide and its composites for environmental applications, each approach being illustrated though several articles which treat the subject. Three potential uses are highlighted, the use of the materials for sorption characteristics against priority pollutants, organic or inorganic, the use for sensors which can monitor and alert the raise in the pollutants concentration in a specific area and the use of graphene oxide materials as aids in analytical techniques that aim to monitor the concentration of environmental pollutants via methods developed in the lab. Another aspect which is treated in this study is the toxicity of those materials, based on the principle that to improve a technique, to remove pollutants from the environment, the material which does so must not be a pollutant in itself.

\section{Environmental depollution using graphene oxide materials}

\subsection{Environmental depollution through adsorption}

In the last few years (2013-2016), a variety of materials have been developed that can potentially be used as sorbents for environmental pollutant species, be them organic or inorganic. The development of those type of materials can prove crucial for mankind, because despite the fact that our society has evolved considerably technologically, a large part of the population still lacks sources of potable water that is free of toxic contaminants. The development of new materials that can bring clean water to populations which are lacking must therefore be one of the main motors of the scientific community and an important milestone in scientific progress.

One important fact about sorbent materials is that those materials must not be more toxic than the pollutants they want to remove, must have potential of reusability, good sorbent capacity and when possible must perform in a variety of working conditions, hence must possess certain versatility. Another important aspect is the production cost and the potential costs of regeneration of the sorbent, given the fact that countries which are in dire need of water sources are mainly poor countries or countries which lack the technological means to properly purify their waters.

Graphenic materials, amongst which graphene oxide and materials based on graphene oxide, took a huge leap forward mainly due to the amount of funding received, from many funding agencies interested in developing new materials that would improve the technologies presently at our disposal. According to the review published by Gaurav Lalwani et al. [57] the European Union invested 1.3 billion dollars over 10 years in the graphene flagship project, Korea invested 44 million spend over 5 years on the same topic, United Kingdom invested 50 million pounds and Huawei Technologies, a Chinese company, invested 1 billion to improve graphemic technologies. Due to the high amount of funding, many different materials were developed, involving the use of graphene oxide, either in pristine state, or modified, physically or chemically, or through the formation of multi-material composites with new properties. The main properties targeted were electronic properties that would enable those materials to be implemented in new generations of electronic equipment, but in several situations, the materials obtained had other properties which made them more suitable for other applications, such as the case of sorbents for water purification.

All the reported papers show good retention properties for pollutant species, using some quite ingenious pollutants that are chosen as model, both from the organic field and from the inorganic one. The inorganic range targeted by publishers covers heavy metals, chromium(VI) being the subject of several articles due to its increased toxicity. One other model used was uranium oxide, which was used to emphasize the sorbent behaviour towards radioactive nuclides, sorbent which could prove highly valuable in the case of nuclear accidents. Though highly improbable, due to modernisations operated in nuclear facilities worldwide, the risk involved and the cataclysmic proportions such an event might have completely justifies the development of sorbents which might purify the waters and help with the repopulation of an affected area.

The studied papers emphasize greater sorption capacity for organic compounds reaching a very good sorbent behaviour in the case of methylene blue on a agar/ graphene oxide aerogel, results published by the group of L. Chen et al. [1]. The group of Vilela D. et al. [6] take the sorbent technology to another level making sorbents in the form of microbots which can capture lead by constantly moving through the contaminated solution. Their study reports greater sorption properties in dynamic conditions (through movement of the microbots) than in static conditions (when the microbots are staying motionless), which is to be expected given that most depolutions are done in dynamic mode, either through the use of columns, filters, or simple movement of the particles in the solution via magnetic stirring. The group lead by Harijan, D.K.L. [12, 13] reports two different sorbents based on graphene oxide/polyaniline, both used for the treatment of 
hexavalent chromium ions, the difference being that one of the sorbents has magnetic particles grafted. The material grafted with magnetic particles shows a lesser adsorption capacity, but provides the final material with magnetic separation capabilities, which makes it easier for the material to be extracted from the solution once the sorption has reached its cycle via application of an external magnetic field.

Removal of the sorbent of the material via external magnetic field seems to be a highly-sought characteristic in a material, and many groups $[3,5,6,8,13-15,21,26,30]$ decided to give their material this feature to simplify their approach towards a large scale industrial use application behaviour.

Table 1: Main depollution characteristics.

\begin{tabular}{|c|c|c|c|c|}
\hline Material type & Pollutant removed & $\begin{array}{l}\text { Adsorption } \\
\text { capacity }\end{array}$ & $\begin{array}{l}\begin{array}{l}\text { Number } \\
\text { cycles } \\
\text { reuse }\end{array} \\
\text { for }\end{array}$ & Reference \\
\hline 3D agar/graphene oxide aerogel & Methylene blue & $578 \mathrm{mg} / \mathrm{g}$ & 3 & [1] \\
\hline Reduced graphene oxide supported ferrite hybrids & Sulfonamides & $1-200 \mathrm{ng} / \mathrm{ml}$ & Not reported & [3] \\
\hline Magnetic calcium silicate graphene oxide composite & Acridine orange & Not reported & 3 & [5] \\
\hline Graphene oxide based microbots & Lead & Not reported & Not reported & [6] \\
\hline double charged ionic liquid modified graphene oxide & $\begin{array}{l}\text { Lead, Cadmium, } \\
\text { Nickel, Copper and } \\
\text { Chromium }\end{array}$ & Not reported & Not reported & [8] \\
\hline Silver-graphene oxide nanocomposite & Eosin yellow & Not reported & Not reported & [11] \\
\hline Graphene oxide sheets functionalized with polyaniline & Chromium (VI) & $192 \mathrm{mg} / \mathrm{g}$ & Not reported & [12] \\
\hline Fe3O4/graphene sheets/polyaniline & Chromium (VI) & $153.54 \mathrm{mg} / \mathrm{g}$ & Not reported & [13] \\
\hline $\begin{array}{l}\text { Chitosan decorated with } \mathrm{Fe}_{3} \mathrm{O}_{4} \text { nanoparticles crosslinked } \\
\text { with graphene oxide }\end{array}$ & $\begin{array}{ll}\text { Anionic } & \text { and } \\
\text { cationic dyes }\end{array}$ & Not reported & 4 & [14] \\
\hline $\begin{array}{lccc}\text { Ternary composite: } & \text { halloysite } & \text { nanotubes, } & \mathrm{Fe}_{3} \mathrm{O}_{4} \\
\text { nanoparticles and graphene oxide } & & \\
\end{array}$ & $\begin{array}{l}\text { Rhodamine B and } \\
\text { As(V) }\end{array}$ & Not reported & Not reported & [15] \\
\hline Graphene oxide & $\begin{array}{l}\text { Levofloxacin and } \\
\text { lead }\end{array}$ & $\begin{array}{l}256.6 \text { and } 227.1 \\
\mathrm{mg} / \mathrm{g}\end{array}$ & Not reported & [17] \\
\hline Graphene oxide & $\begin{array}{l}\text { Naphthalene, } 1- \\
\text { naphtol } \\
\text { cadmium }\end{array}$ & $\begin{array}{l}145, \quad 282 \\
35.7 \mathrm{mg} / \mathrm{g}\end{array}$ & Not reported & [20] \\
\hline Magnetic $\beta$-cyclodextrin-graphene oxide nanocomposites & Malachite green & $740.74 \mathrm{mg} / \mathrm{g}$ & 5 & [21] \\
\hline Graphene oxide & Uranium & Not reported & Not reported & [22] \\
\hline $\mathrm{TiO}_{2}$-Graphene oxide aerogel & Copper & $39.8 \mathrm{mg} / \mathrm{g}$ & $\begin{array}{l}\text { Highly } \\
\text { regenerative }\end{array}$ & [24] \\
\hline Graphene oxide/chitosan & Methylene blue & $168 \mathrm{mg} / \mathrm{g}$ & Not reported & [28] \\
\hline
\end{tabular}

\subsection{Photocatalytic degradation}

Photocatalytic degradation of pollutants channels light energy with the purpose of breaking down molecular bonds and making smaller molecules which are easier to introduce in the earth cycle of reusability.

The research groups [31-36] studied modified graphene oxide's photocatalytic properties against benzene, methylene blue, rhodamine B and NO gas, herbicides, all groups postulating the larger use of their material in the case of organic dye depollution or herbicide degradation. Photocatalytic degradation is one of the important depollution methods, since the solution of depollution provided deals also with the final degradation of the pollutant. In the case of sorbents, the adsorbed species must be dealt with, or reused if possible, after removal from water, in the case of photodegradation the pollutants follow, after degradation, a normal environmental fate, through microbial degradation and afterwards reintegration in nature's great flow of reusability.

The groups chose different types of modification, with anatase phase of $\mathrm{TiO}_{2}$ [31], with $\mathrm{TiO}_{2}-\mathrm{Bi}_{2} \mathrm{O}_{3}$ [34], silver/silver chloride [35] and silver nanoparticles [36]. Different types of modification in the graphene oxide material make the material more suitable towards different types of photo-degradation, each modification changing the catalytic behaviour. Basically, the catalytic behaviour could be tailored via functionalization, and the catalyser can be designed according to the particular needs of each pollutant, in order to maximize the degradation rate of a certain type of pollutant if needed or a 
mixture of pollutants, through proper adjustment of the particles grafted inside the graphene oxide or through the modification of the physical properties of the graphene oxide.

\section{Novel sensor materials}

The research in the field of sensors studied in this articles follows the detection of uranyl [39] and nitrate and nitrite [37], both important ions in the case of water monitoring. Uranyl fast determination in waters that surround mining sites and power plants is one of the main concerns in the nuclear processing industry, and faster, cheaper and more sensitive means to monitor this specific nuclide which exists in nature are always highly sought and highly welcomed. The limit of detection achieved by the group led by Li M.H. [39] is reported to be as low as $86 \mathrm{pM}$, with a dynamic range that spans two orders of magnitude. Nitrate and nitrite are common contaminants in all waters, their presence making many potable sources unsafe to drink. The electrode proposed as sensor by Bagheri $\mathrm{H}$. et al [37] constitutes an alternate technique in water monitoring, giving a quick response with a low limit of detection $(30 \mathrm{nM}-$ nitrate and $20 \mathrm{nM}$ - nitrite) and a good dynamic range $(0.1$ to $75 \mu \mathrm{M})$. The development of good sensor materials can replace the need of costly field excursions for sampling and could also help with source monitoring over larger periods of time.

\section{Materials for sample preparation}

Table 2: Sample preparation technique.

\begin{tabular}{|c|c|c|c|c|}
\hline Material involved & Analytical technique used & Improvement type & $\begin{array}{l}\text { Number of } \\
\text { cycles for } \\
\text { reuse }\end{array}$ & Reference \\
\hline $\begin{array}{l}\text { Graphene oxide }- \text { silica composite } \\
\text { reinforced hollow fibers }\end{array}$ & $\begin{array}{l}\text { Solid phase microextraction of } \\
\text { sulfadiazine }\end{array}$ & $\begin{array}{l}\text { Linear dynamic range } 5-150 \\
\mu \mathrm{g} / \mathrm{L} \\
\text { DL } 1.5 \mu \mathrm{g} / \mathrm{L}\end{array}$ & disposable & {$[40]$} \\
\hline $\begin{array}{l}\text { Magnetite/graphene oxide } \\
\text { nanoparticles }\end{array}$ & Sudan dyes & $\begin{array}{l}\text { Sensitivity, specificity and } \\
\text { low cost }\end{array}$ & $\begin{array}{l}\text { Not } \\
\text { specified }\end{array}$ & [41] \\
\hline Graphite oxide & $\begin{array}{l}\text { Solid phase extraction of } \\
\text { Copper and Lead }\end{array}$ & $\begin{array}{l}\text { DL } 1.25 \mu \mathrm{g} / \mathrm{L} \mathrm{Cu} \\
\text { DL } 2.56 \mu \mathrm{g} / \mathrm{L} \mathrm{Pb}\end{array}$ & $\begin{array}{l}\text { Reusable } \\
150 \text { times }\end{array}$ & {$[42]$} \\
\hline oxide/polyaniline & $\begin{array}{l}\text { Solid phase extraction for } \\
\text { pharmaceutical and personal } \\
\text { care products from wastewater }\end{array}$ & $\begin{array}{l}\text { Ability to detect trace } \\
\text { amounts with good recovery } \\
\text { rates in very complex } \\
\text { matrices }\end{array}$ & $\begin{array}{l}\text { Not } \\
\text { reported }\end{array}$ & [44] \\
\hline $\begin{array}{l}\text { Reduced graphene oxide } / \mathrm{Fe}_{3} \mathrm{O}_{4} / \text { gold } \\
\text { nanocomposite }\end{array}$ & $\begin{array}{l}\text { Magnetic solid-phase } \\
\text { extraction of organo-chlorine } \\
\text { pesticides }\end{array}$ & $\begin{array}{l}\text { Agent-free } \frac{2}{2} \text { microwave } \\
\text { assisted method; Linear } \\
\text { detection range } 0.05-500 \\
\mu \mathrm{g} / \mathrm{L} \\
\text { DL } 0.4-4.1 \mathrm{ng} / \mathrm{L}\end{array}$ & $\begin{array}{l}\text { Not } \\
\text { reported }\end{array}$ & [46] \\
\hline $\begin{array}{l}\text { Magnetic allylamine modified } \\
\text { graphene oxide-poly(vinyl acetate-co- } \\
\text { divinylbenzene) (MGO-DVB-VA) }\end{array}$ & $\begin{array}{l}\text { Magnetic solid phase } \\
\text { extraction of } \mathrm{Pb}, \mathrm{Cd}, \mathrm{Cu}, \mathrm{Ni} \\
\text { and } \mathrm{Co}\end{array}$ & DL 37-239 $\mu \mathrm{g} / \mathrm{L}$ & $\begin{array}{l}\text { Not } \\
\text { reported }\end{array}$ & [47] \\
\hline Graphene oxide coated column & Solid phase microextraction & DL 0.0005-0.005 $\mu \mathrm{g} / \mathrm{L}$ & $\begin{array}{l}\text { Not } \\
\text { reported }\end{array}$ & {$[48]$} \\
\hline Graphene oxide & Solid phase extraction & $\begin{array}{l}\text { DL } 0.08-0.65 \mathrm{ng} / \mathrm{g} \\
\text { Good solvent stability }\end{array}$ & 10 & {$[50]$} \\
\hline
\end{tabular}

\section{Toxicity of graphenic materials}

The toxicity of graphene oxide materials is rather difficult to estimate, mainly due to the fact that the toxic response depends largely on the production method, on the shape of the final composites obtained, on the impurities in the final product, which generally increase the toxic behaviour. The main mechanisms of toxicity produced by graphene oxide are interference with the electron transport system and activation of the MAPK and TGF- $\beta$ signalling pathways. Both result in cell death. In both cases, the death of cells occurs via graphene mediated ROS (reactive oxygen species) damage. 


\section{Conclusions and perspectives}

One of the main advantages possessed by carbon based materials is its biodegradability after it reaches its final stage of usefulness, but it is not the main one. The toxicity of graphene oxide and graphene oxide materials was proved to depend highly on the shape and size of those materials, and through a carefully chosen shape the impact on the environment through subsequent disposal after the complete life cycle can be minimised sufficiently. The studied graphene oxide materials all target pollutants which pose a great concern towards the environment, being they organic in nature (dyes, pharmaceutical products, pesticides) or inorganic (hexavalent chromium, lead, uranium, copper ions), and report good and very good sorption capacities for the targeted pollutants. The fact that the very same materials can be used specifically for their sorption characteristics in other types of application, for example in sensors or sample preparation methods or analytical techniques is another important quality and interesting feature, which has very high practical importance. The only real challenge that remains in the future is sending those materials to work, in the help of societies which still lack access to clean water, a challenge which can only be tackled globally, a challenge which is too great to be ascertained by one person or one research group alone. Towards this goal, a more practical aspect would be to unify the research methods, all groups that deal with sorbents need to reach the common understanding that they must be able to relate each sorbent to what was previously done and to what will be done in the future, and that a more thorough approach does not necessarily involve the destruction of creativity and the promotion of routine work.

\section{Acknowledgements}

The present work was possible due to the EU-funding grant POSCCE-A2O2.2.1-2013-1, Project No. 638/12.03.2014, code SMIS-CSNR 48652. The financial contribution received from the national project 'New nanostructured polymeric composites for centre pivot liners, centre plate and other components for the railway industry (RONERANANOSTRUCT)', No: 18 PTE (PN-III-P2-2.1-PTE-2016-0146) is also acknowledged.

\section{References}

[1] L. Chen, Y. H. Li, Q. J. Du, Z. H. Wang, Y. Z. Xia, E. Yedinak, et al., "High performance agar/graphene oxide composite aerogel for methylene blue removal," Carbohydrate Polymers, vol. 155, pp. 345-353, 2017.

[2] F. Yu, Y. Li, S. Han, and J. Ma, "Adsorptive removal of antibiotics from aqueous solution using carbon materials," Chemosphere, vol. 153, pp. 365-385, 2016.

[3] J. R. Wu, H. Y. Zhao, R. Chen, P. H. Chuong, X. H. Hui, and H. He, "Adsorptive removal of trace sulfonamide antibiotics by water-dispersible magnetic reduced graphene oxide-ferrite hybrids from wastewater," Journal of Chromatography B-Analytical Technologies in the Biomedical and Life Sciences, vol. 1029, pp. 106-112, 2016.

[4] X. B. Wang, L. H. Zhu, L. B. Wan, and H. Q. Tang, "Adsorption of bisphenolic xenoestrogens on graphene: A peculiar adsorbate concentration dependence on the conformation of graphene," Journal of Environmental Chemical Engineering, vol. 4, pp. 2333-2341, 2016.

[5] H. Wang, Y. N. Chen, and Y. M. Wei, "A novel magnetic calcium silicate/graphene oxide composite material for selective adsorption of acridine orange from aqueous solutions," Rsc Advances, vol. 6, pp. 34770-34781, 2016.

[6] D. Vilela, J. Parmar, Y. F. Zeng, Y. L. Zhao, and S. Sanchez, "Graphene-Based Microbots for Toxic Heavy Metal Removal and Recovery from Water," Nano Letters, vol. 16, pp. 2860-2866, 2016.

[7] V. J. Thomas and S. Ramaswamy, "Application of Graphene and Graphene Compounds for Environmental Remediation," Science of Advanced Materials, vol. 8, pp. 477-500, 2016.

[8] Z. Lotfi, H. Z. Mousavi, and S. M. Sajjadi, "Covalently bonded double-charged ionic liquid on magnetic graphene oxide as a novel, efficient, magnetically separable and reusable sorbent for extraction of heavy metals from medicine capsules," Rsc Advances, vol. 6, pp. 90360-90370, 2016.

[9] X. G. Li, W. F. Chen, C. D. Zhang, Y. Li, F. F. Wang, and W. Chen, "Enhanced dehydrochlorination of 1,1,2,2tetrachloroethane by graphene-based nanomaterials," Environmental Pollution, vol. 214, pp. 341-348, 2016.

[10] P. Kumarathilaka, V. Jayaweera, H. Wijesekara, I. R. M. Kottegoda, S. R. D. Rosa, and M. Vithanage, "Insights into Starch Coated Nanozero Valent Iron-Graphene Composite for Cr(VI) Removal from Aqueous Medium," Journal of Nanomaterials, 2016. 
[11] T. Jeyapragasam, "Synthesis of Silver-Graphene Oxide nanocomposite for removal of anionic dye by adsorption," Materials Today-Proceedings, vol. 3, pp. 2146-2154, 2016.

[12] D. K. L. Harijan and V. Chandra, "Polyaniline functionalized graphene sheets for treatment of toxic hexavalent chromium," Journal of Environmental Chemical Engineering, vol. 4, pp. 3006-3012, 2016.

[13] D. K. L. Harijan and V. Chandra, "Magnetite/graphene/polyaniline composite for removal of aqueous hexavalent chromium," Journal of Applied Polymer Science, vol. 133, 2016.

[14] K. Gul, S. Sohni, M. Waqar, F. Ahmad, N. A. N. Norulaini, and A. K. M. Omar, "Functionalization of magnetic chitosan with graphene oxide for removal of cationic and anionic dyes from aqueous solution," Carbohydrate Polymers, vol. 152, pp. 520-531, 2016.

[15] C. W. Gao, B. J. Li, N. Chen, J. Ding, Q. Cai, J. M. Zhang, et al., "Novel Fe3O4/HNT@ @GO composite via a facile co-precipitation method for the removal of contaminants from aqueous system," Rsc Advances, vol. 6, pp. 4922849235, 2016.

[16] I. Duru, D. Ege, and A. R. Kamali, "Graphene oxides for removal of heavy and precious metals from wastewater," Journal of Materials Science, vol. 51, pp. 6097-6116, 2016.

[17] S. N. Dong, Y. Y. Sun, J. C. Wu, B. J. Wu, A. E. Creamer, and B. Gao, "Graphene oxide as filter media to remove levofloxacin and lead from aqueous solution," Chemosphere, vol. 150, pp. 759-764, 2016.

[18] K. J. Yang, B. L. Chen, and L. Z. Zhu, "Graphene-coated materials using silica particles as a framework for highly efficient removal of aromatic pollutants in water," Scientific Reports, vol. 5, 2015.

[19] W. Wang, Y. L. Cheng, T. Kong, and G. S. Cheng, "Iron nanoparticles decoration onto three-dimensional graphene for rapid and efficient degradation of azo dye," Journal of Hazardous Materials, vol. 299, pp. 50-58, 2015.

[20] J. Wang and B. L. Chen, "Adsorption and coadsorption of organic pollutants and a heavy metal by graphene oxide and reduced graphene materials," Chemical Engineering Journal, vol. 281, pp. 379-388, 2015.

[21] D. X. Wang, L. L. Liu, X. Y. Jiang, J. G. Yu, and X. Q. Chen, "Adsorption and removal of malachite green from aqueous solution using magnetic beta-cyclodextrin-graphene oxide nanocomposites as adsorbents," Colloids and Surfaces a-Physicochemical and Engineering Aspects, vol. 466, pp. 166-173, 2015.

[22] C. L. Wang, Y. Li, and C. L. Liu, "Sorption of uranium from aqueous solutions with graphene oxide," Journal of Radioanalytical and Nuclear Chemistry, vol. 304, pp. 1017-1025, 2015.

[23] S. Sen Gupta, I. Chakraborty, S. M. Maliyekkal, T. A. Mark, D. K. Pandey, S. K. Das, et al., "Simultaneous Dehalogenation and Removal of Persistent Halocarbon Pesticides from Water Using Graphene Nanocomposites: A Case Study of Lindane," Acs Sustainable Chemistry \& Engineering, vol. 3, pp. 1155-1163, 2015.

[24] J. R. Xie, J. Y. Li, L. Q. Zhao, X. L. Zhang, B. W. Yu, R. H. Wu, et al., "Fabrication of TiO2-Graphene Oxide Aerogel for the Adsorption of Copper Ions," Nanoscience and Nanotechnology Letters, vol. 6, pp. 1018-1023, 2014.

[25] O. Sayar, K. Mehrani, F. Hoseinzadeh, A. Mehrani, and O. Sadeghi, "Comparison of the performance of different modified graphene oxide nanosheets for the extraction of $\mathrm{Pb}(\mathrm{II})$ and $\mathrm{Cd}(\mathrm{II})$ from natural samples," Microchimica Acta, vol. 181, pp. 313-320, 2014.

[26] W. Lu, Y. Wu, J. Chen, and Y. Yang, "Facile preparation of graphene-Fe3O4 nanocomposites for extraction of dye from aqueous solution," Crystengcomm, vol. 16, pp. 609-615, 2014.

[27] X. W. Zhao, B. Hu, J. J. Ye, and Q. Jia, "Preparation, Characterization, and Application of Graphene-Zinc Oxide Composites (G-ZnO) for the Adsorption of $\mathrm{Cu}(\mathrm{II}), \mathrm{Pb}(\mathrm{II})$, and $\mathrm{Cr}(\mathrm{III}), "$ Journal of Chemical and Engineering Data, vol. 58, pp. 2395-2401, 2013.

[28] S. T. Yang, J. B. Luo, J. H. Liu, Q. H. Zhou, J. Wan, C. Ma, et al., "Graphene Oxide/Chitosan Composite for Methylene Blue Adsorption," Nanoscience and Nanotechnology Letters, vol. 5, pp. 372-376, 2013.

[29] J. Xu, H. D. Lv, S. T. Yang, and J. B. Luo, "Preparation of graphene adsorbents and their applications in water purification," Reviews in Inorganic Chemistry, vol. 33, pp. 139-160, 2013.

[30] Q. H. Wu, C. Feng, C. Wang, and Z. Wang, "A facile one-pot solvothermal method to produce superparamagnetic graphene-Fe3O4 nanocomposite and its application in the removal of dye from aqueous solution," Colloids and Surfaces B-Biointerfaces, vol. 101, pp. 210-214, 2013.

[31] H. M. Yadav and J. S. Kim, "Solvothermal synthesis of anatase TiO2-graphene oxide nanocomposites and their photocatalytic performance," Journal of Alloys and Compounds, vol. 688, pp. 123-129, 2016. 
[32] M. Shanmugam, A. Alsalme, A. Alghamdi, and R. Jayavel, "In-situ microwave synthesis of graphene-TiO2 nanocomposites with enhanced photocatalytic properties for the degradation of organic pollutants," Journal of Photochemistry and Photobiology B-Biology, vol. 163, pp. 216-223, 2016.

[33] M. J. Islam, D. A. Reddy, R. Ma, Y. Kim, and T. K. Kim, "Reduced-graphene-oxide-wrapped BiOI-AgI heterostructured nanocomposite as a high-performance photocatalyst for dye degradation under solar light irradiation," Solid State Sciences, vol. 61, pp. 32-39, 2016.

[34] C. S. Chen, S. Y. Cao, H. Long, G. P. Qian, Y. H. Tsang, L. Gong, et al., "Highly efficient photocatalytic performance of graphene oxide/TiO2-Bi2O3 hybrid coating for organic dyes and NO gas," Journal of Materials Science-Materials in Electronics, vol. 26, pp. 3385-3391, 2015.

[35] Y. L. Min, G. Q. He, Q. J. Xu, and Y. C. Chen, "Self-assembled encapsulation of graphene oxide/Ag@ $\mathrm{AgCl}$ as a Zscheme photocatalytic system for pollutant removal," Journal of Materials Chemistry A, vol. 2, pp. 1294-1301, 2014.

[36] Y. Wang, Y. H. Tang, Y. Chen, Y. Li, X. N. Liu, S. L. Luo, et al., "Reduced graphene oxide-based photocatalysts containing Ag nanoparticles on a TiO2 nanotube array," Journal of Materials Science, vol. 48, pp. 6203-6211, 2013.

[37] H. Bagheri, A. Hajian, M. Rezaei, and A. Shirzadmehr, "Composite of $\mathrm{Cu}$ metal nanoparticles-multiwall carbon nanotubes-reduced graphene oxide as a novel and high performance platform of the electrochemical sensor for simultaneous determination of nitrite and nitrate," Journal of Hazardous Materials, vol. 324, pp. 762-772, 2017.

[38] Y. Y. Sun, J. Tian, L. Wang, H. Y. Yan, F. X. Qiao, and X. Q. Qiao, "One pot synthesis of magnetic graphene/carbon nanotube composites as magnetic dispersive solid-phase extraction adsorbent for rapid determination of oxytetracycline in sewage water," Journal of Chromatography A, vol. 1422, pp. 53-59, 2015.

[39] M. H. Li, Y. S. Wang, J. X. Cao, S. H. Chen, X. Tang, X. F. Zhu, et al., "Ultrasensitive detection of uranyl by graphene oxide-based background reduction and RCDzyme-based enzyme strand recycling signal amplification," Biosensors \& Bioelectronics, vol. 72, pp. 294-299, 2015.

[40] E. Kazemi, A. M. H. Shabani, and S. Dadfarnia, "Application of graphene oxide-silica composite reinforced hollow fibers as a novel device for pseudo-stir bar solid phase microextraction of sulfadiazine in different matrices prior to its spectrophotometric determination," Food Chemistry, vol. 221, pp. 783-789, 2017.

[41] M. Y. Zhang, M. M. Wang, Y. L. Hao, X. R. Shi, and X. S. Wang, "Effective extraction and simultaneous determination of Sudan dyes from tomato sauce and chili-containing foods using magnetite/reduced graphene oxide nanoparticles coupled with high-performance liquid chromatography," Journal of Separation Science, vol. 39, pp. 1749-1756, 2016.

[42] E. Yavuz, S. Tokalioglu, H. Sahan, B. Yilmaz, and S. Patat, "Graphite Oxide Solid-Phase Extraction of Copper(II) and Lead(II) from Water, Food, Tobacco, and Hair," Analytical Letters, vol. 49, pp. 2193-2206, 2016.

[43] A. Wasik, A. Kot-Wasik, and J. Namiesnik, "New Trends in Sample Preparation Techniques for the Analysis of the Residues of Pharmaceuticals in Environmental Samples," Current Analytical Chemistry, vol. 12, pp. 280-302, 2016.

[44] M. Rashvand and M. Vosough, "Graphene oxide-polyaniline nanocomposite as a potential sorbent for dispersive solid-phase extraction and determination of selected pharmaceutical and personal care products in wastewater samples using HPLC with a diode-array detector," Analytical Methods, vol. 8, pp. 1898-1907, 2016.

[45] M. S. Qureshi, A. R. B. Yusoff, M. D. H. Wirzal, Sirajuddin, J. Barek, H. I. Afridi, et al., "Methods for the Determination of Endocrine-Disrupting Phthalate Esters," Critical Reviews in Analytical Chemistry, vol. 46, pp. 146-159, 2016.

[46] A. Mehdinia, S. Rouhani, and S. Mozaffari, "Microwave-assisted synthesis of reduced graphene oxide decorated with magnetite and gold nanoparticles, and its application to solid-phase extraction of organochlorine pesticides," Microchimica Acta, vol. 183, pp. 1177-1185, 2016.

[47] M. Khan, E. Yilmaz, B. Sevinc, E. Sahmetlioglu, J. Shah, M. R. Jan, et al., "Preparation and characterization of magnetic allylamine modified graphene oxide-poly(vinyl acetate-co-divinylbenzene) nanocomposite for vortex assisted magnetic solid phase extraction of some metal ions," Talanta, vol. 146, pp. 130-137, 2016.

[48] F. Tan, C. Zhao, L. J. Li, M. Liu, X. He, and J. S. Gao, "Graphene oxide based in-tube solid-phase microextraction combined with liquid chromatography tandem mass spectrometry for the determination of triazine herbicides in water," Journal of Separation Science, vol. 38, pp. 2312-2319, 2015. 
[49] X. Q. Zhang, S. Chen, Q. Han, and M. Y. Ding, "Preparation and retention mechanism study of graphene and graphene oxide bonded silica microspheres as stationary phases for high performance liquid chromatography," Journal of Chromatography A, vol. 1307, pp. 135-143, 2013.

[50] L. Yu, P. W. Li, Q. Zhang, W. Zhang, X. X. Ding, and X. P. Wang, "Graphene oxide: An adsorbent for the extraction and quantification of aflatoxins in peanuts by high-performance liquid chromatography," Journal of Chromatography A, vol. 1318, pp. 27-34, 2013.

[51] E. Yavuz, S. Tokalioglu, H. Sahan, and S. Patat, "A graphene $/ \mathrm{Co}_{3} \mathrm{O}_{4}$ nanocomposite as a new adsorbent for solid phase extraction of $\mathrm{Pb}(\mathrm{II}), \mathrm{Cu}(\mathrm{II})$ and $\mathrm{Fe}(\mathrm{III})$ ions in various samples," Rsc Advances, vol. 3, pp. 24650-24657, 2013.

[52] X. L. Wu, H. J. Hong, X. T. Liu, W. B. Guan, L. X. Meng, Y. Ye, et al., "Graphene-dispersive solid-phase extraction of phthalate acid esters from environmental water," Science of the Total Environment, vol. 444, pp. 224$230,2013$.

[53] A. Montagner, S. Bosi, E. Tenori, M. Bidussi, A. A. Alshatwi, M. Tretiach, et al., "Ecotoxicological effects of graphene-based materials," 2d Materials, vol. 4, 2017.

[54] Y. L. Zhao, J. N. Yang, and D. Y. Wang, "A MicroRNA-Mediated Insulin Signaling Pathway Regulates the Toxicity of Multi-Walled Carbon Nanotubes in Nematode Caenorhabditis elegans," Scientific Reports, vol. 6, 2016.

[55] Y. L. Zhao, R. H. Jia, Y. Qiao, and D. Y. Wang, "Glycyrrhizic acid, active component from Glycyrrhizae radix, prevents toxicity of graphene oxide by influencing functions of microRNAs in nematode Caenorhabditis elegans," Nanomedicine-Nanotechnology Biology and Medicine, vol. 12, pp. 735-744, 2016.

[56] W. Wu, L. Yan, Q. Wu, Y. J. Li, Q. Y. Li, S. Y. Chen, et al., "Evaluation of the toxicity of graphene oxide exposure to the eye," Nanotoxicology, vol. 10, pp. 1329-1340, 2016.

[57] G. Lalwani, M. D'Agati, A. M. Khan, and B. Sitharaman, "Toxicology of graphene-based nanomaterials," Advanced Drug Delivery Reviews, vol. 105, pp. 109-144, 2016.

[58] A. M. Jastrzebska and A. R. Olszyna, "The ecotoxicity of graphene family materials: current status, knowledge gaps and future needs," Journal of Nanoparticle Research, vol. 17, 2015.

[59] W. Z. Teo and M. Pumera, "Graphene Oxides: Transformations in Natural Waters over a Period of Three Months," Chempluschem, vol. 79, pp. 844-849, 2014.

[60] Q. L. Wu, Y. X. Li, Y. P. Li, Y. L. Zhao, L. Ge, H. F. Wang, et al., "Crucial role of the biological barrier at the primary targeted organs in controlling the translocation and toxicity of multi-walled carbon nanotubes in the nematode Caenorhabditis elegans," Nanoscale, vol. 5, pp. 11166-11178, 2013. 